\title{
Architectural requirement of people with disability in the urban cities in Iraq
}

\author{
Ali Saad Al-Rubaye ${ }^{1}$, Hassan Haider Abdulrazzaq Kamoona ${ }^{2}$, Hadel Saad Razoki Al-Mur'ib ${ }^{3}$ \\ ${ }^{1}$ Architectural Department, Faculty of Engineering, Al-Muthanna University \\ ${ }^{2}$ Department of Reconstruction and projects, University of Baghdad \\ ${ }^{3}$ Architectural Department, Faculty of Engineering, Al-Muthanna University
}

\section{Article Info}

Received Jun 02, 2019

\section{Keyword:}

Disability

Urban environment

Architecture

Human needs

\begin{abstract}
At the international level, attention is focused on the possibility of integrating people with special needs into their communities in a way that reduces their sense of disability by providing their public needs in the urban environment. The architectural and building codes in Arab societies have neglected the humanitarian considerations associated with this category for a long time, where people with disabilities in Arab societies, especially the Iraqi society, have many difficulties that lead to determining their movement in the urban environment of contemporary cities, which has a negative impact on how this group adapts within these societies and the difficulty of their integration, although the Iraqi government has sought to develop the constitution to support people with disabilities, However, these attempts were just theoretical but do not adopt a real binding application for urban development projects in the current reality of the cities in the twenty-first century, which calls for the introduction of real standards with well-studied dimensions and depends on multiple global standards to provide flexible solutions to transform the urban environment into an environment that can embrace the people with disabilities and provide sufficient flexibility in movement solutions which helps to develop their mental and physical abilities in a series and appropriate manner in the current Iraqi society, therefore the research study includes the following:-

- Criteria and requirements of people with special needs in the urban environment to reach the appropriate architectural standards for them.

- Experiences and legislation suitable for people with special needs in third world countries and Arab countries.

- Architectural foundations are suitable for people with special needs in the Iraqi cities.
\end{abstract}

\section{Corresponding Author:}

First Author,

Ali Saad Al-Rubaye,

Architectural Department, Faculty of Engineering,

Al-Muthanna University,

Samawah, Al-Muthanna, Iraq

Email: alisaad@mu.edu.iq 


\section{Introduction}

In the first and second decades of the twentieth century, individual design and implementation attempts have been made in this field, many of which continue to fail because of the lack of real application of strict standards that take into account the needs of this category. This contributes to the ease of movement in the building joints resulting from these designs due to the lack of knowledge of engineering requirements or not to apply or meet with each other to cause a significant obstacle to provide a climate suitable for the integration of this category with the rest of the components of society, and in this sense comes the importance of the study in determining the real standards appropriate to transform the urban environment of Iraqi cities to an environment suitable for the movement of people with disabilities in an easy, simple and innovative way, based on various visual and structural solutions that will vary in the solutions of development of external spaces and traffic paths and entrances of public and residential buildings and vertical means of movement and service spaces to provide the greatest flexibility to support the movement of this important group in the community.

The aim of the study is to study the design and planning considerations suitable for people with special needs in Iraqi cities and the need to benefit from the experiences of countries that have already been in this area, whether advanced or developing, to find suitable solutions that can be applied according to real standards based on legislation that ensures the application of these solutions is ideal.

\section{The Material and Method}

The study is based on the analytical descriptive approach in presenting the social problems of people with special needs and their requirements. The study deals with the experiences and legislations in the countries of the developed world and the Arab countries in order to be able to know the problem and the appropriate design methods to formulate real solutions for it at the architectural levels in the interior design of the building itself and the urban outside in roads.

\section{Theory}

\subsection{Disability and disabled setting size in Iraq}

Before starting to study the problems and requirements of people with special needs in the Iraqi urban environment, different methods of classification of multiple disabilities should be clarified so that we can study their problems:-

\subsection{Classification}

Medical disabilities are classified into: -

Physical disability: - disability resulting from dysfunction of the nerves or muscles or bones and joints, leading to loss of motor power to the body as a result of amputation, spinal injuries, muscular dystrophy, and its relaxation and her death, rheumatism [1].

- Sensory disability: - disability resulting from an injury to nerves sensory organs such as the eye or ear or tongue produces a Visual or auditory sensory disability or hearing disability ratio. Head and neck approximately $21.6 \%$ of total [1].

- Intellectual disability: - disability resulting from defect in senior positions for the brain, as focus and counting, memory and communication with others, resulting in learning disabilities or learning difficulty, or faulty behavior and General conduct of person [1].

- Mental disability: - disability resulting from mental disease or hereditary diseases or cerebral palsy as a result of lack of oxygen, or the result of genetic disorders or all that impedes the mind from the known functions [1].

- Dual Disability: - presence of delays per person [1].

- Composite Disability: - is a collection of various disabilities have per person [1]. Emphasis has been architecturally on the following:-

\subsubsection{Sensory disabilities}

Featuring the behavioral effects and personal tracking individual and the most are:

- Grow his attention in motion and depends on others assistance in several areas.

- Use his hearing to recognize sounds and determine distances and obstacles are dynamic spaces must be provided free of soundproof materials or pipette it.

- Using the sense of touch to identify texture sizes and shapes and surfaces for non-diversification must be unjustified termination materials and elements brushes for the psychological effect. 
- Braille communication is representing a preferred way to communicate and its own a big potential for visually handicapped that choice to rely on the various extension movement and multiple spaces and denote mock names or public moral.

\subsubsection{Physical disability}

Which is the basic element on the architectural study of the impact of disability carried significant impact across artificial limbs used by means of daily communication and movement and one of the most important human qualities:-

- Turning traffic to sit in a wheelchair and the depending on others help for move it that's why it's limited to streets and accompanying person in the back to secure the momentum.

- Difficulty moving for a long time with poor balance and difficulty bending and slow motion.

- Weak support members as feet and forearms.

\subsection{Size of the disabled in Iraq}

The study relied on data available on the disabled in Iraq are the Population censuses and the last scan in 2007 IHSES [2] conducted the socio-economic survey of the family in Iraq and Population censuses: -

Table (1) shows the total number of persons with disabilities according to the environment, sex, and population censuses of the country in 1977, 1987, and 1997 [3]. The percentage is doubled during the years 1977 to 1987 due to the IraqiIranian war, the Gulf War and the circumstances in Iraq. And decreased from 1.7 to 1.3 between 1987 and 1997. The main reason for this decline was the cessation of the Iran-Iraq war, in addition to some increase in some of the services available to them. The total number of persons with disabilities in 1997 is 244817 [4] and is $1.3 \% 0 \%$, which is very low compared to the world rates. The global statistics show that the percentage of disabled persons in developing countries is $10 \%$. This low rate is due to the reluctance of most families to disclose what the family has to people with disabilities due to shyness, as well as the lack of knowledge and diagnosis of disabilities by parents, especially in early childhood.

Table (1) shows that the highest percentage of disabled persons reached $2 \%$ for males in urban areas and the lowest percentage of persons with disabilities in rural areas are females, $0.6 \%$. The percentage of persons with disabilities in Baghdad governorate to persons with disabilities in the country is $33.81 \%$ the percentage of disability in Baghdad was $34 \%$ for the mentally weak, followed by the percentage of those with visual impairments (30.7\%), followed by those with paralysis (30.53\%), the rest the ratios between $25 \%$ and $2 \%$ (1977-1987, 1997 census) [5].

Table 1. The distribution of the population with disabilities by gender and environment and caused them to the total population, According to the General Population Census for the years 1997, 1987, 1977 [3]

\begin{tabular}{|c|c|c|c|c|c|c|c|}
\hline \multicolumn{5}{|c|}{ The countryside } & \multicolumn{5}{c|}{ Urban area } & \multirow{2}{*}{ year } \\
\hline total & Female & male & total & Female & male & type of people & \multirow{2}{*}{1977} \\
\hline 36660 & 13169 & 23491 & 74435 & 28654 & 25781 & persons with disabilities & \\
\hline 4354443 & 2151094 & 2203349 & 7646054 & 3666505 & 3979549 & total population \\
\hline 0.8 & 0.6 & 1.1 & 1.0 & 0.8 & 1.2 & Percentage of disabilities \\
\hline \hline 75116 & 22214 & 52902 & 200412 & 62222 & 138190 & persons with disabilities & \multirow{1}{*}{1987} \\
\hline 4866230 & 2421744 & 2444486 & 11468969 & 5527566 & 5951403 & total population \\
\hline 1.5 & 0.9 & 2.2 & 1.7 & 1.1 & 2.3 & Percentage of disabilities \\
\hline \hline 623767 & 17985 & 45386 & 181446 & 53958 & 127488 & persons with disabilities & \multirow{2}{*}{$\mathbf{1 9 9 7}$} \\
\hline 623767 & 3168522 & 3070245 & 12945776 & 6479451 & 6466326 & total population \\
\hline 10.2 & 0.6 & 1.5 & 1.4 & 0.8 & 2.0 & Percentage of disabilities & \\
\hline
\end{tabular}

\begin{tabular}{|c|c|c|c|}
\hline \multicolumn{3}{|c|}{ Total } & \multirow[b]{2}{*}{ year } \\
\hline total & Female & male & \\
\hline 111095 & 41823 & 69272 & \multirow{3}{*}{1977} \\
\hline 12000497 & 5817599 & 6182898 & \\
\hline 0.9 & 0.7 & 1.1 & \\
\hline 275528 & 84436 & 191092 & \multirow{3}{*}{1987} \\
\hline 16335199 & 7939310 & 8395889 & \\
\hline 1.7 & 1.1 & 2.3 & \\
\hline 244817 & 71943 & 172874 & \multirow{3}{*}{1997} \\
\hline 19184543 & 9647973 & 9536570 & \\
\hline $1 / 3$ & 0.7 & 1.8 & \\
\hline
\end{tabular}




\subsection{International experience}

\subsubsection{European countries and America}

European countries differ in dealing with the problems of the disabled. The follower of the situation of the disabled in Denmark finds that it is not related to a government policy aimed at integrating the disabled, and the quality of educational services provided to the disabled. While in England and France, federal laws provided multi-faceted support for integration into schools, although students with mental disabilities were isolated from their peers in mainstream schools. In Germany, children with mental disabilities were successfully integrated into integration schools in 9 of 11 states, and government schools accepted students with disabilities who could follow the mainstream curriculum. In 1975, the federal law was passed in the United States, which stipulated that special education should be provided to all who needed it, and the right of children with disabilities to receive education, free integration into the less restrictive environment and the restriction of normal schools. A large number of students with light disabilities and middle school students were merged with their peers who did not have a disability of the same age, but the students with the most severe disabilities remained in American schools [6].

\subsubsection{Arabic States}

In the Arab States, there is a discrepancy in the focus on the issue of integrating disabled persons into public education. In Jordan, the Disabled Persons Law was promulgated in 1992, in which the Ministry of Education was given the task of educating the Ministry of

Education. This responsibility was the responsibility of the Ministry of Social Development. Which has developed a five-year project that was implemented in three phases. In the United Arab Emirates, special education classes included 1060 students, and learning resource rooms have been introduced in regular schools since the beginning of 1990 . In Bahrain, disability issues were distributed among the Ministry of Education in the remedial classes. In 1992, the integration experience was implemented in a school for males and for females. A law on disabled persons in Libya in 1972 provided for the State guarantee of basic education for persons with disabilities. A Tunisian law issued in 1991 provided for the State guaranteeing the right of persons with disabilities to free and compulsory education, which was implemented in the same year in 35 schools. Students with disabilities in Syria receive their services in specialized centers and institutions, and integration ideas are still being studied and evaluated. The situation in Egypt and Morocco is different from the rest of the Arab countries mentioned earlier, where the schools of special education are still isolated from regular schools, although there are many calls to apply the idea of integrating students with disabilities in public education [7].

The Arab Regional Conference, held in Beirut from 7 to 10 May 2001, under the theme of integrating disabled persons into formal education. The experiences of five Arab countries in the integration issue are Lebanon, Morocco, Saudi Arabia, Yemen and Egypt.

In Lebanon, the experience of integrating disabled persons into public schools began in the early 1980s by the civil society and at the official governmental level. The work started in 1999 and the civil society activities on this issue included an attempt to develop educational programs in the centers of NGOs to attend regular schools. Individual initiatives were initiated by some parents and institutions in the integration of various disabilities including deaf, sight and motor disabilities. An attempt was made to document these experiments with a field study. The results showed difficulties in the following areas:-

- Training and training of breeders.

- Accepting the civil society for the disabled to attend regular schools.

- Implementation of integration in the basic stage, while it is easy to join children with disabilities to kindergarten.

The results were presented at a general conference held in 1993, followed by a group of individuals who sought to reflect on the policy of integration in an attempt to develop the best strategy for the spread of integration in regular schools. These efforts remained scattered until 1999, when they intervened. Ministry of Education through the Educational Center for Research and Development in cooperation with UNESCO, and asked three specialists to prepare a report on the situation of the disabled in Lebanon.

This report showed the Ministry of Education's lack of a comprehensive policy on the education of the disabled, as well as the problem of teacher training and the lack of specialists in this field [7].

The report was accompanied by the preparation of the first national conference on disability education in Lebanon, held in 1999, during which the results of the national report raised some of the field experiences that contribute to the expression of this issue.

At the conclusion of the first conference, six areas were identified for field research: -

(Organizing and legislation, awareness and information, research and documentation, educational programs and methods, training, pilot experiments). The research was conducted by about 80 volunteers from all employees, in 2000 , the Second National Conference on the Education of the Disabled was held in Lebanon. The results of the field studies were presented and recommendations were made in each of the six areas to consolidate the strategy of educating people 
with disabilities by selecting an educational area. Concerned and all civil society groups, parents and persons themselves, to reflect a model empirical work structure based on:-

- Diagnosis, early intervention, rehabilitation and education in formal and private formal schools.

- Training of workers in the sector.

- Educate and educate parents, students and the community.

The project shall be evaluated after one year of its implementation prior to the necessary amendments and generalization. In fact, there is no field follow-up to implement the recommendations and action plan for many reasons. But what we can deduce in this context is the existence of an active civil society in Lebanon that has managed to reach the highest levels of official and national education. As a result, Lebanon has taken some steps to institutionalize the affairs of persons with disabilities, all of which still have many obstacles in the educational system. 70\% of the schools are private schools and the status of public schools is very poor. On 6/6/2000, There is a clear paragraph that obligates schools to receive the disabled, but without specifying the appropriate mechanisms to implement this. The card of the person known as the disabled card is still issued by the Ministry of Social Affairs [7].

\subsubsection{Syrian Arabic Republic}

The Syrian Arab Republic has taken steps on the path of integration. The most important results were drawn from this experience during the last period:

Accept the idea of integration among many educators and accept work with special cases.

The warm and sincere emotional atmosphere between ordinary children and the disabled, which indicates that the error lies within the adults, and the young language of their own communication.

Adjust the negative attitudes toward disabled people.

Increasing attention to the issues of persons with disabilities and seeking to meet their needs tomorrow is easier than before, which shows the increase of awareness and acceptance of the other among the members of society [8].

\subsubsection{Situation in Iraq}

The Iraqi government issued the law on the care of all disabled persons to guarantee their rights, especially the texts of articles (20/19/18/17/16/15/3/2), where the text of those articles includes rights, privileges and even penalties according to the provisions of the following law:-

According to the provisions of Article (1) of Article (61) and Article (III) of Article (73) of the Constitution, the following law was issued:

\section{No. (38) For the year 2013}

Law on care of people with disabilities and special needs - Chapter II

Goals and means

Article (2) this law aims to achieve the following:

Care for people with disabilities and special needs and eliminate discrimination due to disability or special needs.

Create the integration of people with disabilities and special needs in society.

Provide a decent life for people with disabilities and special needs.

Respect disability and accept disability as part of human diversity and human nature.

To create employment opportunities for people with disabilities and special needs in the government departments and the public sector, mixed and private.

Article (3) the objectives of this law shall be achieved by the following means:

Develop special plans and programs to ensure the rights of persons with disabilities and special needs in accordance with the provisions of the law and the international conventions and conventions to which the Republic of Iraq is a party.

Accession to international agreements and conventions on the care of people with disabilities and special needs.

Develop programs and plans to prevent the causes of disability and make them available to raise awareness.

Securing therapeutic requirements, social services, psychological and vocational rehabilitation for persons with disabilities, and special needs for cooperation and coordination with relevant bodies inside and outside Iraq.

Provide public and private education opportunities and vocational and higher education for people with disabilities and the special needs of those who can afford it.

Development of staff working in the field of care for people with disabilities and special needs and the establishment of a database for them and update them [9].

The use of expertise and specialization and keep abreast of scientific developments in everything related to disability and special needs and contact with the competent authorities inside and outside Iraq to raise the efficiency of performance in this area.

Holding conferences, seminars, scientific meetings and training and rehabilitation courses inside and outside Iraq.

Disability grants and special needs special identities.

Encourage the manufacture of equipment and equipment needed by people with disabilities and special needs. 
The law lacks precise application and real follow-up of this category in all aspects of life and does not confirm any legal provisions forcing the government departments and private and mixed companies operating in all state facilities to provide the real needs of engineering in the field of architecture and urban planning for this category accurately and practically in the Iraqi urban environment [9].

\subsection{Architectural foundations in the urban environment for People with disability in Iraq}

Spaces in buildings and external environment can be divided into below kinds:-

\subsubsection{External environment}

The external environment, for example, includes streets, squares, pedestrian paths, parks and playgrounds. It is important to enable persons with special needs to move between buildings or other places or to walk or perform any activities abroad.

A city identity is necessary and essential as it delivers harmony between the "constant" and the "changing" elements [10] When planning the outdoor environment, take into consideration wheelchairs users, whether manual or electrical. [11]

\subsubsection{Pedestrian areas}

The width of the walkway should be at least $1.80 \mathrm{~m}$ and a width of not less than $0.90 \mathrm{~m}$ to enable wheelchair users to pass these roads as in (Fig.1).
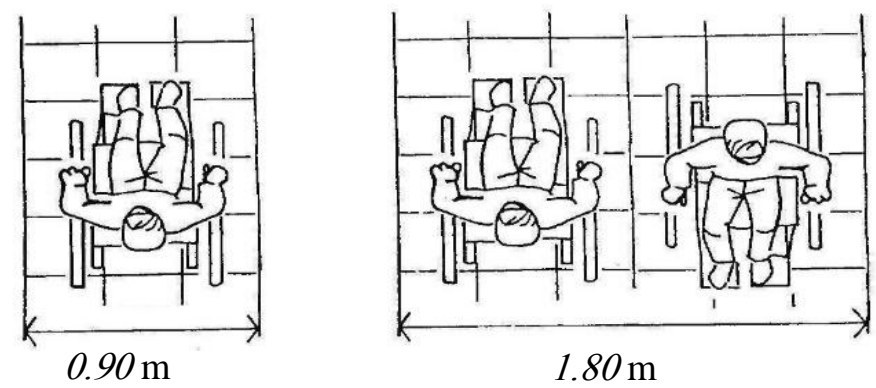

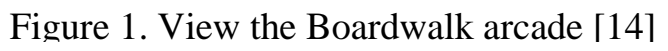

- Surfaces must be solid pedestrian lanes and slip-resistant.

- There should be a clear difference between the surface footpaths and part of asphalt or grass for easy directing of suffering from poor eyesight.

- Must be the surrounding fields or specific characteristic surfaces large areas as in (Fig.2) .

- Awareness of the problems of housing and urban environments [12].

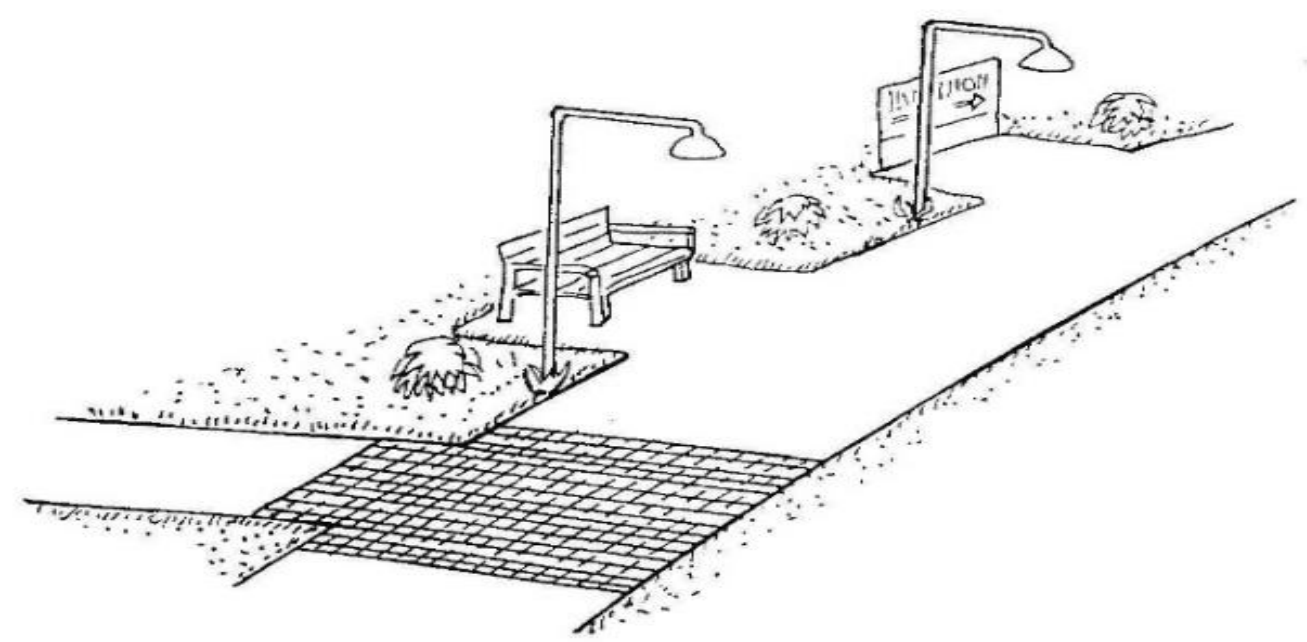

Figure 2. Lanes [14] 


\subsubsection{Pedestrians paths}

- If there is an intersection between a pedestrian passage and another or a street, there should be a clear change in the surfaces to attract the attention of those with impaired vision of these intersections (transit place).

- Pavement plazas are created by converting space on the sidewalks of main streets to usable pedestrian plaza or commercial space [13].

- $\quad$ Lighting poles, signs, seats on the sides of corridors should be placed.

- Seats should be provided along the long walkways.

- The walkways should be well lit [14].

- Creating decorative architectural module that can effectively reduce air pollution when installed near traffic ways on building facades. Modules would be made from lightweight thermoformed plastic panels coated with TiO2 [15].

- Creating innovative plant locations to solve the main problem in the field of air pollution by industry which is the use of geo-ecologically unacceptable production technologies that are not in accordance with best available technologies (BAT). Pollutants emitted from agriculture to the environment are ammonia (NH3), methane (CH4) and nitrous oxide (N2O) [16].

\subsubsection{Pedestrian crossing}

- The location of pedestrians crossing and distinguishing them from the rest of the corridor should be clarified by the diversity of surfaces.

- The crossing must be perpendicular to the pavement, and when there are traffic lights, it must be equipped with sound signals.

- There should be diversity in the surfaces of the transit areas.

- The width of the island at the middle of the footpath should be at least $1.5 \mathrm{~m}$ as shown in (Fig.3) to enable wheelchair users to stand on it.

- Pedestrian width should not be less than $1.80 \mathrm{~m}$ to allow wheelchair users to cross.

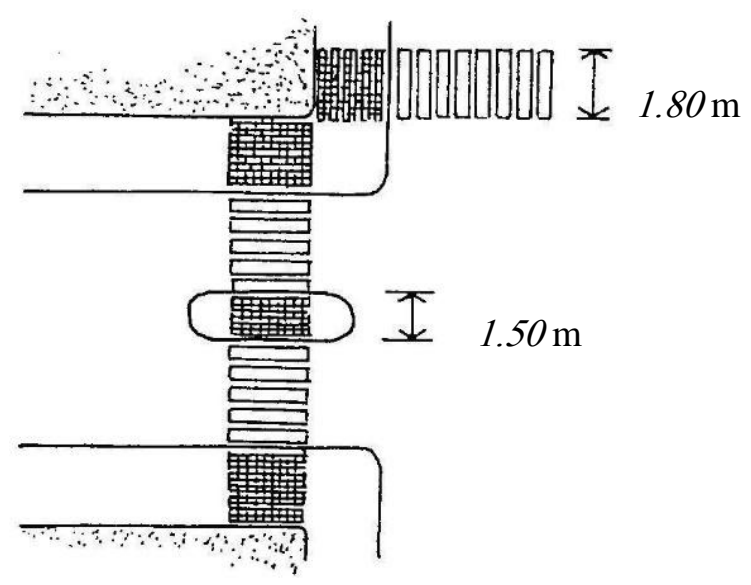

Figure 3. Pedestrian crossing lines dimensions [14]

\subsubsection{Parking}

- Parking spaces for persons with motor disabilities must be close to the entrances in public buildings, commercial centers, other service buildings to enable maneuverability for the wheelchair next to the car with the possibility of opening the door of the full car we need space Sufficient as in (Fig.4).

- A minimum distance of $3.5 \mathrm{~m}$ should be provided in disabled parking spaces to allow wheel maneuvering [11]. 


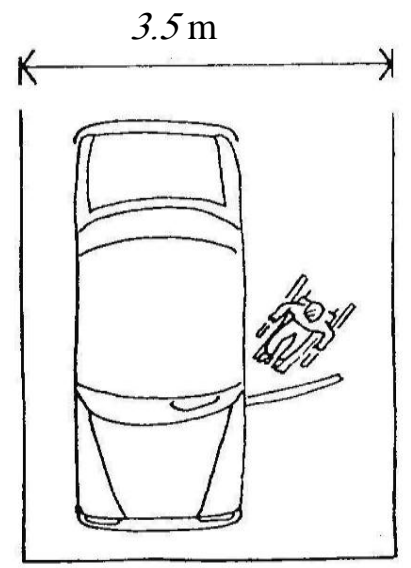

Figure 4. Car parking [14].

\subsubsection{Doorways and distribution terminals}

- In the case of design of entrances suitable to the needs of persons with disabilities, the facilities and facilities on which the design of the entrance is based will vary between a public building with a large number of users, whether wheelchair users or not, and dwellings whose entrance is usually used only for one person at the same time.

- In the interior spaces of the public buildings, a difference can be made between the crowded distribution halls, which require special specifications for the vacuum or the internal distribution halls for areas of limited use such as toilets, refer to the door section to meet their requirements.

\subsubsection{Entrances}

- The entrance to the building must be shaded, for example an indoor or an umbrella, and such a procedure can also help to distinguish the entrance for people with visual impairment.

- Space should be provided without any barriers or obstructions that are no less than the dimensions in the figure to provide space for wheelchair users to approach the entrance in preparation for transit.

- Surfaces must be slip-resistant.

- The openings must not exceed $15 \mathrm{~m}$.

- A handrail should be placed next to the entrances to help people with motor disabilities.

- It is recommended to avoid rotating doors if any alternative doors are found at the entrance of the wheelchairs for people with motor disabilities [14].
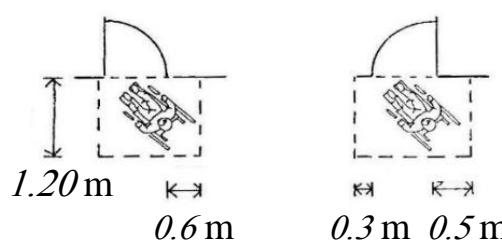

$0.3 \mathrm{~m} 0.5 \mathrm{~m}$

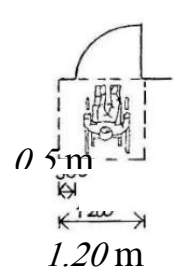

$1.20 \mathrm{~m}$

$$
\underset{k \rightarrow x}{0.50}
$$
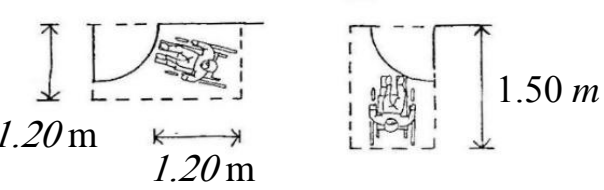

Figure 5. Space of doors [14]
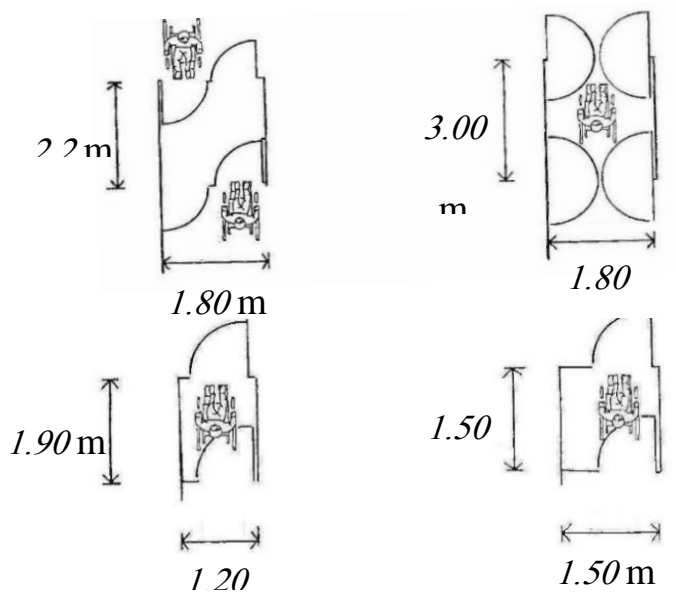

Figure 6. Lobby doors to public buildings [14]. 


\subsubsection{Lobby doors}

- If there is an entrance hall in a public building, sufficient space should be provided to allow the chair maneuverability and dimensions as shown in (Fig.5).

- If there is an entrance hall in the private housing, sufficient space should be provided to allow the chair maneuverability and dimensions as in (Fig.6).

- In the case of the threshold of the entrance must be below the surface of the floor to be the same level of the adjacent surfaces and must be of solid materials.

- In the entrance to a door leading to private accommodation, additional space must be provided in the entrance to allow wheelchair rotation [11].

Figure 6. Lobby doors to

public buildings

Figure 7. Domestic lounges [14]
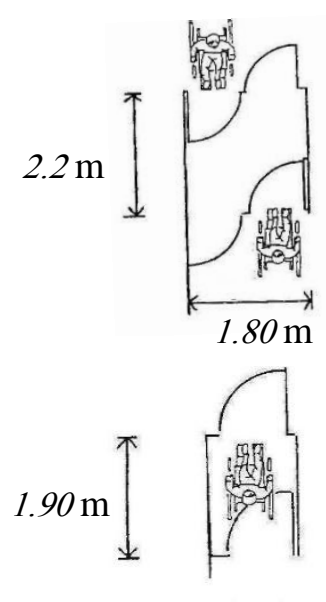

$\mathrm{k} \longrightarrow$

$1.20 \mathrm{~m}$
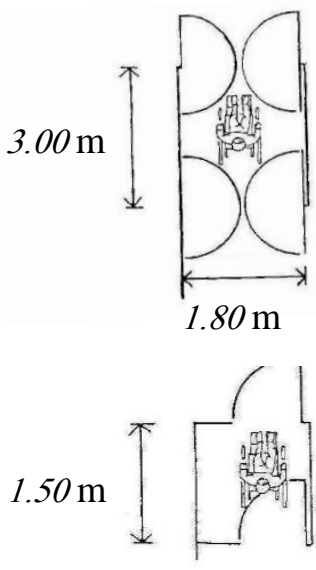

$k+1$

$1.50 \mathrm{~m}$

\subsubsection{Interior hallways in public buildings}

- The interior corridors of the public buildings must have a large area that allows for the free movement and maneuvering of the wheelchairs.

- Double-sided doors should be designed as shown in (Fig.6).

- Single-door lobbies should be designed to separate busy traffic areas and internal traffic as (FIGURE 7.) a. In the case of limited motion, the spaces are reduced as shown in (Fig.6) b.

- In bathrooms, one coat holder should be placed at minimum height of $1.20 \mathrm{~m}$ above ground level for ease of access from the wheelchair, and should not be prominent so as not to pose a potential hazard.

- Provide sufficient space for wheelchair mobility.

- The reception areas must be clarified and marked, and the reception should allow use of wheelchairs. [14].
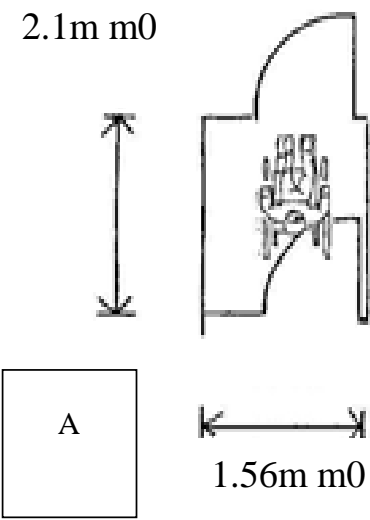

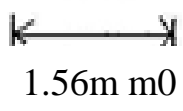

$2.20 \mathrm{~m}$

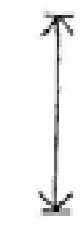

B

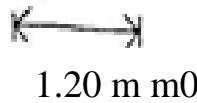

Figure 7. Domestic lounges [14]. 


\subsubsection{Public buildings}

\subsubsection{Interior hallways with private accommodation}

Interior hallways for private residences should be designed as they are in (Fig.7).

\subsubsection{Elevator cabins and controls}

The elevator entrance must be on the same level as the entrance of the building. It should also be accessible by wheelchair users from all floors of the building.

\subsubsection{Elevator cabins}

- To facilitate the access of wheelchair users to buildings, the dimensions of the elevator must not be less than 1.10 * $1.40 \mathrm{~m}$.

- Must be in accordance with the standard specifications in the case of only one elevator in the building.

- However, the elevator cabin does not allow $1.10 * 1.40 \mathrm{~m}$ wheelchair dimensions, so a lift should be provided with larger dimensions if higher accessibility is required as in (Fig.8).

- Sliding doors must be used automatically according to the standard specifications, and the time to open the door should be sufficient to allow the wheelchair to pass.

- The net width of the door, which allows the wheelchair to pass at least $0.80 \mathrm{~m}$.

- It is useful to have the door of the elevator of color contrasted with the wall next to the easy orientation of the visually impaired.

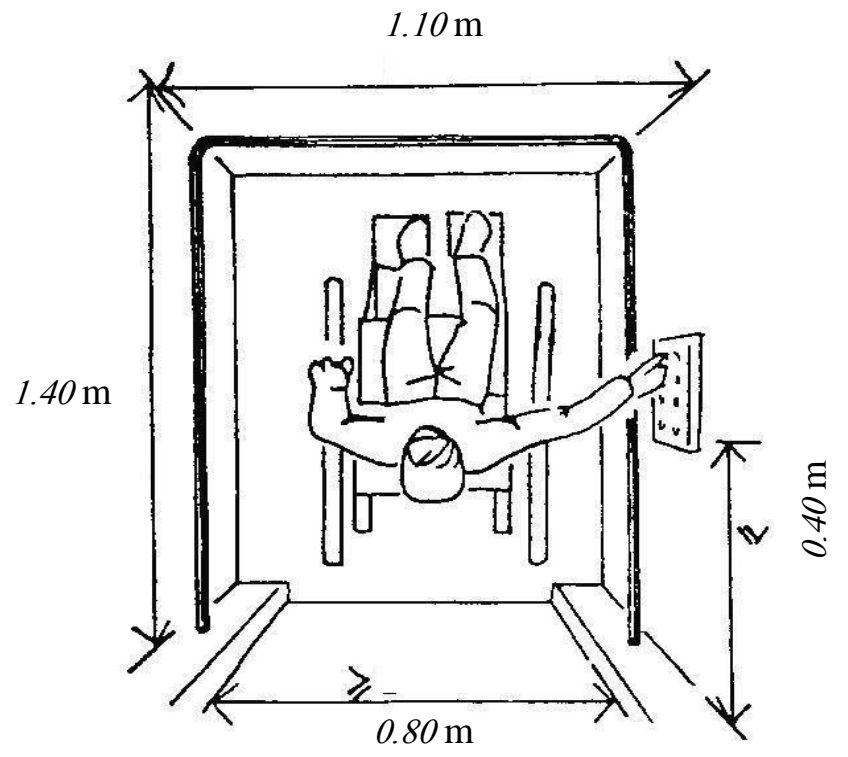

Figure 8. Cabins lift [14]

- Enough space for wheelchair maneuvering should be provided in front of the elevator doors to enable wheelchair users to enter and exit the elevator easily (Fig.9).

- There should be no difference in the levels between the elevator floor and the floor in front of him in order to avoid the dangers of accidents. This is especially important if driving the wheelchair back inside or outside the elevator.

- It is preferable to equip the elevator cabin with a handle in the inner perimeter of the cab at a height of $0.90 \mathrm{~m}$ from the floor level to support the handicapped.

- The floor of the elevator cab must be finished with a slip-resistant material.

- The elevator cabin lighting should be good and non-reflective [11]. 


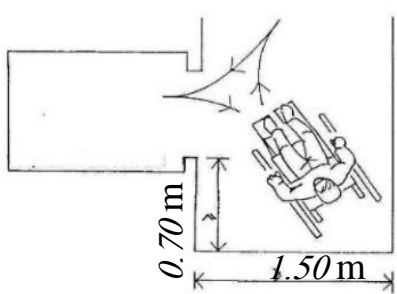

Figure 9. Net vacuum before the elevator door [14]

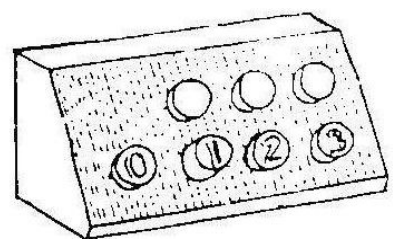

Figure 10. Control panels [14]

\subsubsection{Control devices}

- The elevator controls should be placed at a height of 0.90 to $1.20 \mathrm{~m}$ above the ground level so that wheelchair users can access them, and should not be placed at a very low altitude so as not to be difficult for the visually impaired to use.

- Controllers should be placed at a distance of $0.40 \mathrm{~m}$ from the cabin or cabin doors for easy access by wheelchair users.

- The controls must be placed in a regular and orderly manner. The diameter of any button should not be less than $0.025 \mathrm{~m}$. At least $1 \mathrm{~cm}$ between the buttons should be left for easy use by persons with weak or weak coordination between the arms and hands or the visually impaired.

- The touch of the button on the ground floor must be marked and has a different color.

- The buttons should be contrasted with the background color to help the visually impaired to use them.

- Symbols should be of different colors and be easy to understand. Figures and symbols should be prominent for ease of reading by touch [14].

- It is useful to place the control devices and symbols at an angle on the wall to facilitate the process of reading and maneuvering as in (Fig.10).

\subsubsection{Access to bathrooms}

- In the design of bathrooms for residential buildings and to achieve the minimum of general needs may mean the lack of all the health systems in full (for example, it may be impractical overlap of access to health devices together) in this case must be clarified all the information available to achieve the best practical solution.

- When designing health appliances in public housing or private housing, attention must be paid to the needs of people with special needs, especially with regard to the vacuum required to reach all health systems.

- When designing a vacuum, the main concern should be to provide a suitable wheelchair entry.

- The vacuum of the water cycle should allow a forward, lateral and lateral movement of the toilet as in (Fig.11).

- A suitable space should be provided at one side of the toilet to allow a person or a hand wash basin to be located on the other side, and an area that allows the wheelchair to allow the person to move sideways in public buildings as shown in (Fig.12).

- Provide sufficient space to allow easy movement of the person on both sides of the toilet (left and right) [11].

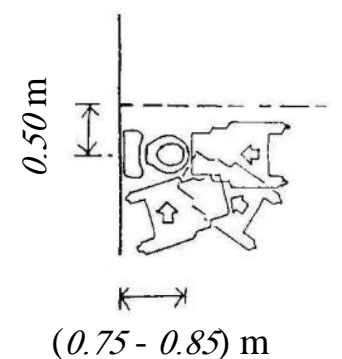

Figure 11. Into the toilet [14]
Side area

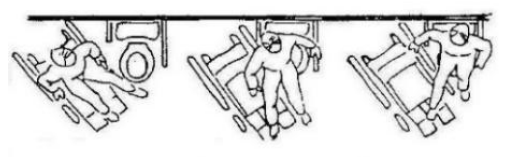

Front

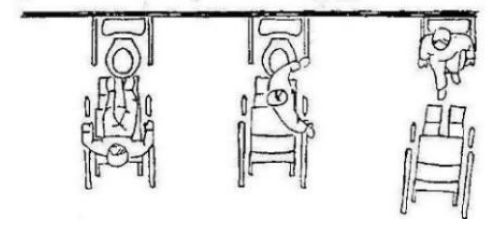

Figure 12. Examples to move from the wheelchair to toilet toilets [14] 
- The available space should allow the front, side, and lateral transition of the wheelchair users. This space is required on each side of the device to allow the facilities to assist the user in moving as in (Fig.13).

- For the hand wash basin, the available front and tilt space should be allowed for wheelchair users as in the (Fig.14).

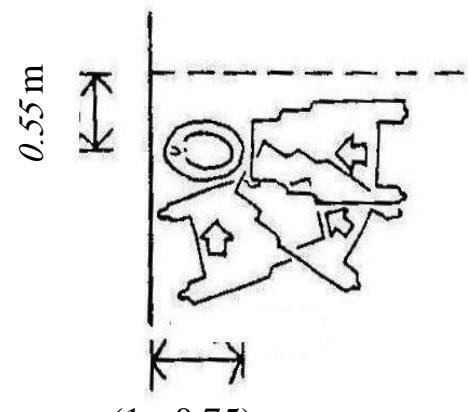

$(1-0.75) \mathrm{m}$

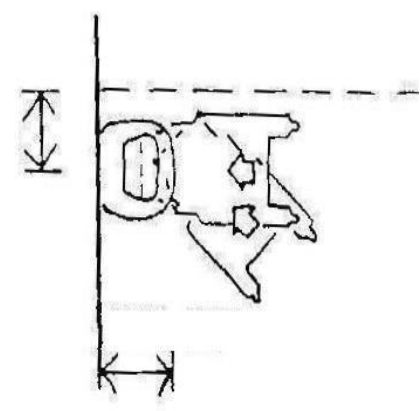

$(0.50-0.55) \mathrm{m}$

Figure 13. Using the toilet [14]

Figure 14. Put washing hands [14]

- It is preferred to have a terrace at the front of the bathtub for the possibility of moving inside the tub with seating as in (Fig.15).

- The spaces within the bathrooms should allow for the front and diagonal approach of the basin as well as the lateral movement of the wheelchair users to the terrace in the bathtub.

- A seat for the disabled should be available for disabled people who cannot stand, with a space that allows lateral wheelchair users to move to the shower seat as shown in (Fig.16).

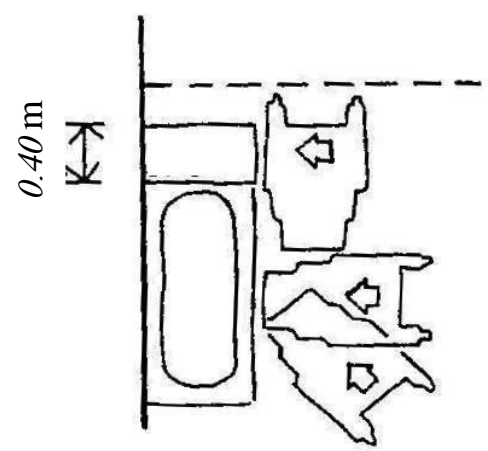

Figure 15. Shower position [14]

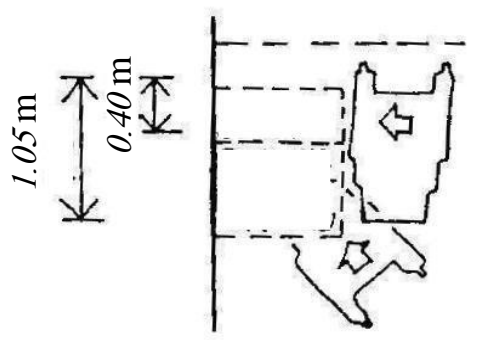

Figure 16. Bathtub position [14]

- Floor surfaces must be non-slip.

- Bathroom fittings must be flexible and equipped to achieve user comfort according to the type of disability.

- The possibility of replacing the bathtub with shower and changing the water mixer should be available with a singlehandle mixer or heat mixer [11].

- L- Kitchens

- The basic purpose of the disabled can be achieved by applying some general requirements in the standard kitchens. In addition, it is possible to rehabilitate the kitchen for more specialized needs for the disabled person residing in residential buildings.

- In this section, some general and common requirements are described. However, the need for clarification and discrimination is based on the actual general requirements that should be achieved locally on all the kitchens that are created and it is best to comply with the greatest number of requirements in general. 


\section{Results}

Guidance systems should use the following order of solutions to maintain a good performance for the urban environment.

\subsection{Routing problem solutions}

Shortages in routing ability cause difficulties in receiving, absorbing and interpreting information, such difficulties depend on the following example:-

- The availability of information in a form of difficult reception for the visually impaired or the hearing impaired

- Provide information in an inadequate and difficult manner to people who are mentally disturbed or mentally disabled

- Put information in a way that is difficult for the physically disabled to reach

- The required guidance requirements are established according to the following:-

1. General planning - facilities and external environment

2. Signboards

3. Colors

4. Illumination

5. Choose materials

6. Different forms of guidance and guidance

An integrated information system is used to take special care of people with different needs. It is also necessary to know where they are and where they go as in (Fig.17), in order to move easily and safely and operate the control keys, elevators and doors (Arabic industrial development and Mining Organization / Center of standardization and Metrology).

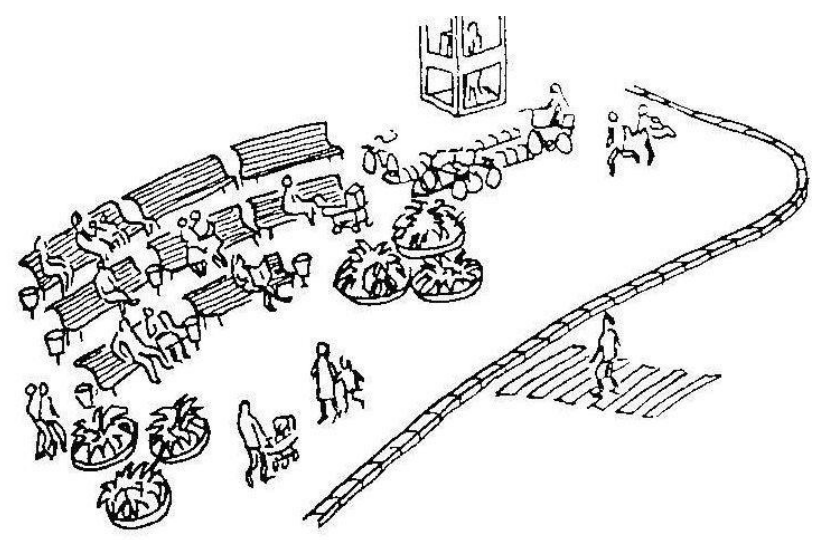

Figure 17. Street equipment groups [14]

\subsection{General layout - facilities and external environment}

- It is important to have a simple and clear general planning, general planning should provide the possibility of achieving perceptions and ideas of the surrounding things including the points of guidance that can be achieved and activated.

- In the general planning of an area the associated services are contiguous.

- Elevators, information desks, telephone booths and separate toilets must be in a clear location, and the electricity management room, instructions and other services are best to be found in regular locations.

- During planning, consider the natural environment that identifies routing problems to avoid risks to buildings and the external environment. Solutions are found to avoid the presence of one degree, columns, protrusions from the wall or glass doors and the like. Consider the acoustics, level of lighting, change of finishes, color variation and other environmental aids.

- Roads and corridors should not be provided with stairs or obstructions. Be suitable for the purpose of use.

- The change in direction should be determined by the difference in materials, colors, lighting, handrails, etc. It is best to use the existing angles when changing direction. 
- Street equipment, shop baskets and wheel paths can be combined to reduce risk. Furniture should be placed so that it does not pose any obstacles.

- If there are obstacles, warnings should be placed in the face of these obstacles. Glass doors, automatic doors, windows, and engraving should be marked with signs [11].

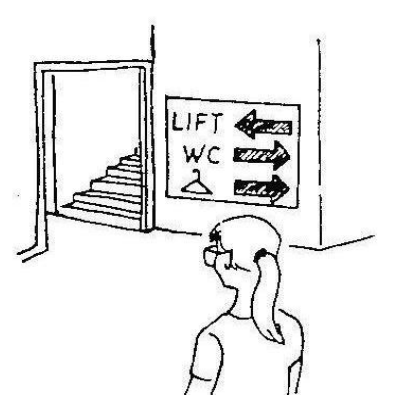

Figure 18. Readable instructions understandable [14]

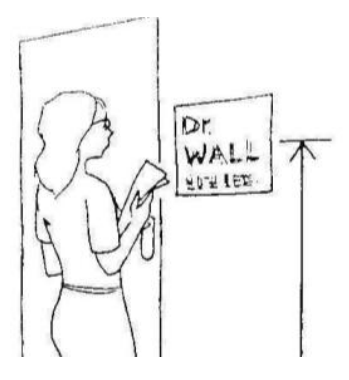

Figure 19. Marking in the fixed places [14]

\subsection{Guidance signs and writings}

- Signs must be readable and understood according to their purpose.

- They should be designed so that they are not ambiguous, simple and easy to interpret, and the information must reflect the user's familiar ideas and experiences.

- Signs should be of strong material and be easy to change, clean and repair.

- Main types of signs

- Direction signs: sketches, diagrams, models, etc. should be placed in accessible places for wheelchair users and others so that they can be easily examined and understood as quietly and conveniently as possible.

- Direction signs: They should be placed in a logical sequence from the starting point to the positions of the different points as in (Fig.18).

- It should be repeated but not in abundance but every place where movement can be changed.

- Functional signage: a non-ambiguous explanation of the activity to which it refers should be given - parking spaces, elevators, separate toilets, etc. as in (Fig.19).

\subsection{Places of signs}

- Wall signs must be placed at an altitude between 1.40 and $1.60 \mathrm{~m}$ above ground level. Hanging signs of ceilings, columns or protruding from the wall that are placed at an inappropriate altitude for optimal reading height should be avoided. However, if this type of signage is chosen, its design should be taken into consideration so that the size of the writing is proportional to the distance from which it is read.

- Signs should be attached in a manner that avoids the presence of reflections.

- Signs should be placed in a specific place on the door frame, wall, columns, etc. instead of doors [14].

\subsection{Topography}

- The use of easy codes can increase user orientation.

- Difficult to understand or unusual characters can lead to difficulty in directing the user.

- It is best to use the easy and familiar style of writing, keeping in mind that the degree of writing is not light or dark.

- The height of the letter shall be 1: 200 of the required reading distance, but the height shall not be less than $0.15 \mathrm{~m}$ and the external gaps shall not be less than $0.10 \mathrm{~m}$.

- In the case of writing in English, CAPITAL LETTER is used for short phrases. Long phrases use lower-case letters, which must be colored in contrast to the background.

- It is preferable to use simple words, with no distance between words, short sentences are easy to understand and remember.

- Should not use abbreviations or long words that are difficult to understand.

- Should leave proper spaces between lines of writing.

- Lines should start from one vertical line and not necessarily equal length. 
- Prominent characters are preferred and should not be too pronounced to avoid being easily read sideways, letters 15 to $40 \mathrm{~mm}$ high and $1 \mathrm{~mm}$ preferred for visually impaired as in (Fig.20) [14].

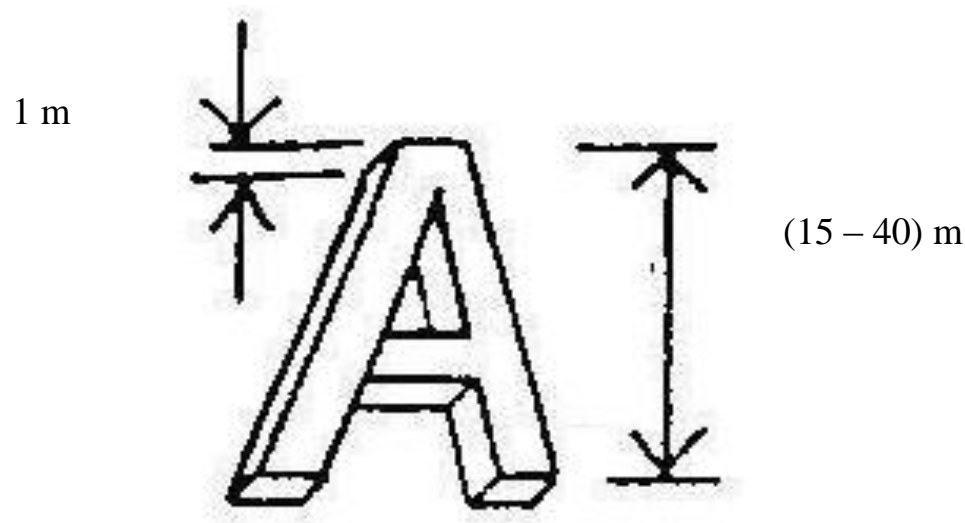

Figure 20. Occurrence of characters [14]

\section{Discussion and Conclusions}

From the previous study we can conclude several recommendations to make the urban environment internally appropriate from the architectural and externally in order to meet the needs of people with special needs in the Iraqi cities, as follows:-

- It is necessary to emphasize the application of the relevant laws to provide the requirements of people with special needs immediately with the creation of specialized tools that support the new terms that could be generated to works in different parts of society in the country.

- The development of specialized agencies inside the higher authority of the government as well as creating legislation for the setting new standards to transform the environment in order to support the new needs

- Updating the components of the urban environment also to deliver them in an appropriate technical level that provides the needs of both normal persons as well as people with special needs.

- Ensure that the existing facilities in the urban environment are applying all the needs of people with disability in civilized and continuous actions.

- Developing the elements of urban furniture by supervising the contractor's jobs and assist in choosing the right norms to deliver a very good level of comfort to both normal and disabled peoples.

\section{Acknowledgments}

This research was supported by dr.Ahmed Abdul Ali. Which he is one of my colleagues from Al-Muthanna University who provided insight and expertise that greatly assisted the research, I would thank also dr.Satar Al-arajy for assistance and comments that greatly improved the manuscript. I would also like to show my gratitude to the head manager of collage of engineering dr.Raed Al-kateb for sharing his pearls of wisdom with us during the course of this research, and also thank the three "anonymous" reviewers for their so-called insights.

\section{References}

[1] A. Ghaida, "Youth Awareness in Bethlehem Governorate - Integration of People with Disabilities in the Community, Panorama Publications,", 2003.

[2] M. o. P. a. D. C. /. C. A. f. S. a. I. Technology, " IHSES Social Survey and Family Economy in Iraq 2007," Ministry of Planning and Development Cooperation / Central Agency for Statistics and Information Technology, iraq, 2007.

[3] C. B. o. S. Ministry of Planning, "General Population Census for 1977, 1987, 1997," Ministry of Planning, Central Bureau of Statistics, iraq, 1977, 1987, 1997.

[4] C. B. o. S. Ministry of Planning, "Statistics of the Disabled, 1997 Census.," Ministry of Planning, Central Bureau of Statistics, iraq, 1997.

[5] S. I. Ismail, "Assessment of the reality of children with special needs in Iraq and the services provided to them," Department of Social Policy / Department of Human Development / Ministry of Planning and 
Development Cooperation / Repunlic of iraq, iraq, 2009.

[6] A. Fatiha, Attitudes of Teachers of the Basic Stage in the City of Jerusalem towards Integrating Students with Special Needs in Public Education, Ramallah, Palestine.: Birzeit University,, 1998.

[7] N. Baslat, Attitudes of School Teachers towards the Integration of Handicapped Children in Government Basic Schools in the Northern West Bank, Sudan: Al-Fasher University, 2003.

[8] a. Abdullatif, "A proposed program to activate the role of partnership between the family and NGOs in the rehabilitation of the disabled in society," in the first conference for community rehabilitation in the Arab countries, Damascus Universit, syria , 2006.

[9] i. government, "Law on the Care of Persons with Disabilities and Special Needs No. (38) For the 2013 im Iraqi Constitution," International Labour Organization (ILO), 2013.. [Online]. Available: http://www.ilo.org/dyn/natlex/natlex4.detail?p_lang=\&p_isn=96874.

[10] S. \&. A. Z. \&. D. N. Hussein, "Urban Regeneration through Post-War Reconstruction: Reclaiming the Urban Identity of the Old City of Mosul,," Periodicals of Engineering and Natural Sciences, p. 4, 2018.

[11] iso.org, "iso.org," iso.org, 1994. [Online]. Available: https://www.iso.org/standard/22799.html.

[12] S. \&. R. N. Yousif, "Role of the academic curriculum in the development of the basic learning outcomes (knowledge - skills - capabilities) of the architect using the method of currere," Al-Nahrain University, Baghdad, Iraq., 2019.

[13] S. \&. A. S. Hussein, "Reviving urban spaces through tactical urbanism in Baghdad: Five common tactics," Al-Nahrain University, Iraq, 2018.

[14] A. O. f. I. D. a. M. -. S. a. M. C. -. E. O. f. S. a. Q. -, "Arabic Draft Standards Project ", Arab Organization for Industrial Development and Mining, Egypt.

[15] M. \&. A. M. Halilovic, "Potential of air quality improvements in Sarajevo using innovative architecture approach," International University of Sarajevo., Bosnia and Herzegovina, 2017.

[16] Z. \&. o. Osmanović, "Construction of bioparks on devastated land in urban areas," Periodicals of Engineering and Natural Sciences, p. 7, 2017. 